\title{
Interrelation of the Population Awareness of the Presence of an Increased Risk of Developing Type 2 Diabetes Mellitus
}

\author{
By Anastasiya Sachkouskaya* \\ Maria Rusalenko ${ }^{+}$ \\ Tamara Sharshakovat \\ Irina Savasteeva ${ }^{+}$
}

\begin{abstract}
Diabetes mellitus (DM) is one of the most important public health problems in the world. The aim of the study is to evaluate the initial level of knowledge of the population about risk factors, the first signs and complications of the disease, and to define the weaknesses of hygienic education of the population. Also we have conducted comparative analysis of the psychosomatic status of patients with Type 2 Diabetes Mellitus (T2DM) and without diabetes. During the study, 300 people were interviewed about awareness of diabetes issues and the 10-year risk of developing T2DM (FINDRISC score) was estimated. Interrelation of the population awareness of an increased risk of developing T2DM was studied. Eating behavior was studied using the Dutch Eating Behavior Questionnaire (DEBQ). Hospital Anxiety and Depression Scale (HADS) was used to assess the psychological and emotional status. Stress-resistance was studied using the Social Readjustment Rating Scale (SRRS). Personality features were assessed using the Toronto Alexithymia Scale. 33\% of respondents of population were not informed about the risk factors for diabetes, $38 \%$ - about the first signs of the disease; $29 \%$ - of possible complications. The largest proportion of factors that significantly influenced the 10-year risk of developing T2DM were modifiable behavioral factors, namely, body mass index (BMI), waist circumference (WC), daily availability of 30-minute activity and consumption of vegetables. About half of the respondents do not follow the recommendations on rational diet, physical activity, smoking cessation and alcohol consumption. Low level of awareness of these issues leads to underestimation of existing risk factors, unwillingness to change the habitual lifestyle and, as a consequence, increases the risk of diabetes. Thus, it is necessary to improve the awareness of both the population and specialists in diabetes issues, increase responsibility of medical staff to the patient, increase the interest of the population to a more conscious and responsible attitude to their own health.
\end{abstract}

Keywords: Awareness, Diabetes mellitus, Prediabetes, Psychosomatic status

\section{Introduction}

Chronic non-communicable diseases (CNCDs) are the leading causes of death throughout the World Health Organization (WHO) European Region. More than $75 \%$ of all deaths are caused by one of four CNCDs - cancers, cardiovascular diseases, diabetes and chronic respiratory diseases. In the Republic of Belarus, as in other countries, CNCDs remain the main cause of morbidity, disability and premature mortality, accounting for $86 \%$ of deaths and $77 \%$ of overall morbidity

\footnotetext{
${ }^{*}$ Assistant Professor, Public Health Department, Gomel State Medical University, Belarus.

${ }^{\dagger}$ Vice Director, Republican Scientific and Practical Center for Radiation Medicine and Human Ecology, Belarus.

Professor \& Head, Public Health Department, Gomel State Medical University, Belarus.

${ }^{+}$Doctor-Statistician, Republican Scientific and Practical Center for Radiation Medicine and Human Ecology, Belarus.
} 
(WHO 2017). According to recent studies, 52\% of the patients who has several CNCDs are persons aged under 65 (WHO 2013). Currently, diabetes has the leading prevalence rate among all non-communicable diseases. The number of people with diabetes has increased from 108 million in 1980 to 422 million in 2014. The global prevalence of diabetes among people over 18 years has increased from $4.7 \%$ in 1980 to $8.5 \%$ in 2014. The prevalence of diabetes is increasing faster in middle- and low-income countries (WHO 2016). According to the International Diabetes Federation (IDF), in 2011, diabetes accounted for about 4.6 million deaths worldwide (IDF 2011). In more than half of cases T2DM occurs in active working age (40-59 years). It must be noted that according to the experts of the IDF the number of people with diabetes aged 20-79 years was predicted to rise to 642 million (uncertainty interval: 521-829 million) by 2040 (Ogurtsova et al. 2017).

Diabetes mellitus is a major public health problem worldwide. This disease has become one of the major causes of premature death in most countries. This is also true to Belarus. In the Republic of Belarus as of January 1, 2017, there were 303,922 patients with diabetes under follow-up, including T1DM - 17,264 people, T2DM - 284,207 people (prevalence 3.5\%), gestational diabetes - 383, other specific types of diabetes $-2,068$. The number of first time diagnosed diabetes has increased of $6-8 \%$ per year over the last 5 years. In the general structure of the prevalence of diabetes mellitus in Belarus, T2DM is $93 \%{ }^{1}$. With the increase in the prevalence of T2DM in Belarus, identifying T2DM at early stage with simple and accurate methods becomes a public health priority.

The role of stress in the etiology of diabetes is difficult to define and measure, but there is significant evidence of its metabolic consequences. Stress is often observed in conjunction with the diagnosis of diabetes and it alters the glucose metabolism and the immune response (Falco et al. 2015). Premorbid psychological features of the personality and its basic parameters (temperament and character) form the basis of any psychosomatosis or psychological trauma. Researchers at the University of Munich identified three main reasons contributing to the development of diabetes in terms of psychosomatic: post-traumatic depression, chronic psychological problems in the family and increased anxiety (Poberey and Mellina 2012). That is why there is the interest in the study of eating disorders accompanied by specific features of thinking and behavior in obesity and T2DM.

An important measure to reduce burden of diabetes is the participation of the patients in the management of their disease. That is why, the main aims of this research are 1) to study the population awareness of the risk factors, symptoms and complications of diabetes mellitus; 2) to estimate 10-year incident of diabetes and evaluate the impact of the level of public awareness on the 10-year risk of developing type 2 diabetes; 3 ) to consider the problem of psychosomatic relationships in diabetes.

Knowledge of the distinctive features of the patient's psychological profile, based on the study of cognitive, emotional and behavioral characteristics, may be

\footnotetext{
${ }^{1}$ Retrieved from https://bit.ly/2NX1mNN. (In Russian)
} 
enable the doctor and patient to interact productively in the process of managing of diabetes.

\section{Literature Review}

The term diabetes mellitus describes a metabolic disorder of multiple aetiology characterized by chronic hyperglycaemia with disturbances of carbohydrate, fat and protein metabolism resulting from defects in insulin secretion, insulin action, or both (ADA 2014, WHO 1999).

A degree of hyperglycemia sufficient to cause pathologic and functional changes in various target tissues, but without clinical symptoms, may be present for a long period of time before diabetes is detected (ADA 2014). Modern laboratory capabilities in diagnostics make it possible to detect the condition of "prediabetes".

"Prediabetes" is the term used for individuals whose glucose levels do not meet the criteria for diabetes but are too high to be considered normal. This term used for individuals with impaired fasting glucose (IFG) and/or impaired glucose tolerance (IGT) and indicates an increased risk for the future development of diabetes (ADA 2015). Currently, a serious problem is in the lack of alertness for both doctors and patients at this stage of the disease.

Prediabetes should not be considered as an independent clinical form of the disease, but rather as an increased risk of developing diabetes and cardiovascular diseases (CVDs). Several research studies have shown success of interventions designed for treatment of prediabetes with sustained reduction in incidence of diabetes. It should be noted that the development of T2DM can be prevented through activities aimed at changing the lifestyle (Bansal 2015, Hopper et al. 2011, Knowler et al. 2002, Li et al. 2008, Lindström et al. 2006, Natangelo et al. 1990).

According to the data of American Diabetes Association (ADA), the United States Diabetes Prevention Program demonstrated that intensive lifestyle interventions (ILS) can reduce the incidence of T2DM by 58\% within 3 years. The biggest determinant of risk reduction was noted to be weight loss (ADA 2017, Lindström et al. 2006, Knowler et al. 2002). Also randomized studies demonstrate that lifestyle modification, which consists only in reducing body weight and increasing physical activity, prevents or slows the progression of glucose metabolism disorders in persons with IGT, which emphasizes the importance of explaining the need for lifestyle modification and assisting in its implementation (Rydén et al. 2014).

Nowadays, $40-50 \%$ of patients with diabetes at the time of diagnosis already have complications associated with the disease (Dedov and Shestakova 2013). The grave complications, such as amputations of lower extremities, blindness and chronic kidney disease adversely affect the ability to work and the quality of life of the patients. Diagnosis of diabetes in the early stages and timely prescribed therapy provide long-term positive results in the treatment of patients with diabetes by preventing or delaying the development of complications (Stratton et al. 2000). Therefore, one of the important goals is to increase the awareness of the general 
population about the risk factors, the opportunities for prevention and early detection of diabetes.

Previous studies have shown that individuals with inadequate health literacy had significantly higher rates of hypertension (49.9\% vs $43.3 \%$ ), diabetes mellitus (18.7\% vs $12.8 \%)$, heart failure (6.1\% vs $3.8 \%)$, and arthritis $(57.3 \%$ vs $50.1 \%)$ with those with adequate skills. Inadequate health literacy was a significant independent predictor of having diabetes mellitus and heart failure (Wolf et al. 2005). Patients with inadequate functional health literacy are also less likely to know basic elements of their care plan for diabetes and hypertension (e.g., low-salt diet, symptoms of hypoglycemia, normal range for blood pressure or blood glucose level) (Williams et al. 1998).

The issues of assessing the level of knowledge of the population about diabetes and its possible relation to development of T2DM have not been yet studied in the Republic of Belarus, which predetermined the aim of the study. The aim of this study is to specify and evaluate the awareness of the population of Belarus about the risk factors, symptoms, complications of diabetes mellitus and basic preventive measures of pathology. Further, in this study we regard the possible correlation between knowledge of population about diabetes and 10-year risk of developing T2DM. Moreover, in the course of the research we interviewed sample of population in order to regard the problem of psychosomatic relationship in diabetes. Through this, we hope to assess the initial level of knowledge of the population about risk factors, the first signs and complications of the disease, and also to identify the weaknesses of health literacy of the population for the purpose of improving diabetes prevention and decrease prevalence of the disease.

\section{Materials and Methodology}

The research data were collected during spring 2017 from the population who applied for medical assistance to outpatient health organizations (organizations which provide primary healthcare in Belarus) in Gomel, Belarus. These institutions were selected as that is exactly where the patients have the first contact with the doctor; and there is possibility to study initial level of knowledge about diabetes. The responders were interviewed by the researcher or filled out the questionnaire by themselves.

The study was approved by the local executive committee of Gomel. All subjects provided informed written consent prior to participation in the study and agreed to anonymous use of their data. The participation was voluntary.

\section{Study of the Population Awareness of Diabetes and its Prevention}

Anonymous questioning was used as an investigation method. The Population Awareness Questionnaire included: 
- personal data (sex, age);

- sections about diet, physical activity, adherence to prevention, smoking and drinking alcohol habits, sources of information on diabetes; and

- questions about the risk factors for the diabetes, symptoms and complications specific for this pathology.

The main exclusion criteria were:

- patients with a diagnosis of diabetes;

- medical workers; and

- patients with acute conditions, exacerbations of chronic diseases, with chronic diseases in the terminal stage, as well as with mental disorders.

\section{Evaluation of the 10-year Risk of Developing T2DM}

The evaluation of the 10-year risk was carried out using the FINDRISC scale proposed by Lindström and Tuomilehto (2003). FINDRISC is a simple selfadministered questionnaire which can be used as an initial diabetes screening in primary care or community settings (Zhang et al. 2014). It takes into account the usual clinical characteristics, such as age (years), body mass index (BMI: $\mathrm{kg} / \mathrm{m}^{2}$ ), waist circumference (WC: $\mathrm{cm}$ ), daily physical activity (having at least 30 minutes of physical activity during work or at leisure time vs. not), daily consumption of fruits, vegetables, and berries (consume every day vs. not), use of antihypertensive medication, history of high blood glucose, and family history of diabetes. BMI and WC were identified from the anthropometric data measured by researchers. The answers to all the other questions of the FINDRISC were identified via selfreported answers.

Interpretation of results was carried out by the sum of the scores from 8 questions and ranges from 0 to 26 (Saaristo et al. 2005, Zhang et al. 2014).

Ten-year risk of developing type-2 diabetes mellitus according to FINDRISC.

- $\quad$ > - Low Estimated: 1 in 100 will develop disease;

- 7-11 - Slightly elevated Estimated: 1 in 25 will develop disease;

- 12-14 - Moderate Estimated: 1 in 6 will develop disease;

- 15-20 - High Estimated: 1 in 3 will develop disease;

- 20 - Very high Estimated: 1 in 2 will develop disease (Lindström and Tuomilehto 2003).

\section{Study of Psychosomatic Relationships in Diabetes}

Eating behavior was studied using the Dutch Eating Behavior Questionnaire (DEBQ). The Dutch Eating Behavior Questionnaire (DEBQ) was developed to measure eating styles that may contribute to or attenuate the development of overweight. It comprises three scales that measure emotional, external and restrained eating (Cebolla et al. 2014). Psychosomatic theory focuses on emotional eating (eating in response to negative emotions such as depression and 
discouragement) as an atypical response to distress. Externality theory emphasizes eating in response to food-related stimuli, such as the sight, smell and taste of food, regardless of the internal state of hunger and satiety. Restraint theory focuses on the possible psychological side effects of dieting, specifically the disinhibition effect: overeating by dieters when their cognitive resolve to eat less than desired is abandoned (Barrada et al. 2016).

Hospital Anxiety and Depression Scale (HADS) was used to assess the psychological and emotional status. The HADS was developed from a study conducted in the outpatient clinic of a general medical hospital. The findings of this study were published by Zigmond and Snaith (1983). The questionnaire comprises seven questions for anxiety and seven questions for depression, and takes 2-5 min to complete (Stern 2014).

Stress-resistance was studied using the Social Readjustment Rating Scale (SRRS). The SRRS was created by Thomas Holmes and Richard Rahe in the late 1960s to provide a standardized measure of the impact of a wide range of common stressors.

Personality features are assessed using the Toronto Alexithymia Scale (TAS). It was developed in 1986. The TAS is a 26-item self-report measure of alexithymia with good internal consistency and test-retest reliability, and a factor structure congruent with the alexithymia construct (Bagby et al. 1986).

\section{Statistical Analyses}

Statistical analyses were carried out using nonparametric statistics, since the distribution within the groups was not normal. The data of descriptive statistics are expressed as mean Me (q1; q3). The Mann-Whitney test was used to detect statistically significant differences. The chi-squared test was used to compare frequencies between the groups, Fisher's method was used in groups with less than 30 respondents.

A linear regression analysis was performed to identify the factors that significantly influenced the stratification of the 10-year risk of developing diabetes mellitus. Statistical analyses were performed with SPSS Statistics 17.0.

\section{Results}

Study of the Population Awareness of Diabetes and its Prevention

The research group consisted of 300 people (Figure 1), of which men - 91 (30.3\%), women - 209 (69.7\%). 
Figure 1. Distribution of Respondents by Sex

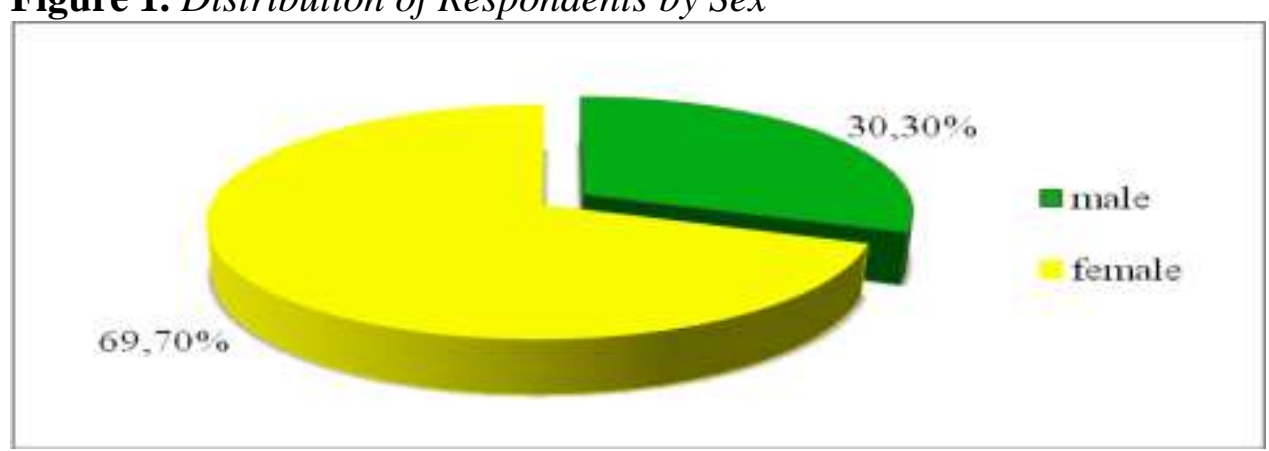

The number of respondents represented by the age group of 18-25 years was $25 \%$. The share of the 26-35 age group was 21\%; $36-45$ years - 15\%. $46-60$ years - 22\%, over 60 years - 17\% (Figure 2). An analysis of the age distribution of the respondents showed that the majority of those who took part in the survey were patients of the young and able-bodied age of 18-59 years - 83\%.

Figure 2. Distribution of Respondents by Age

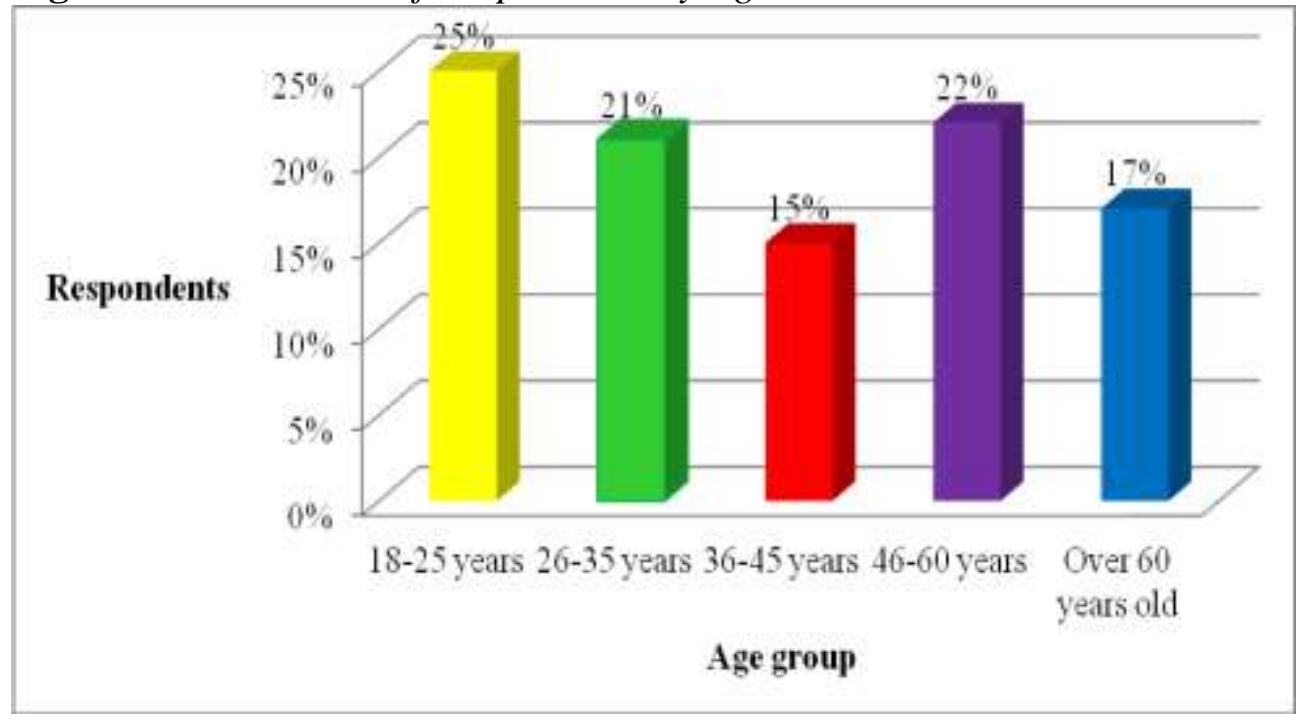

In the course of the study we have analyzed questions about population awareness of the risk factors, main symptoms and complications of diabetes. We asked respondents whether they were aware of risk factors for diabetes. The results showed that the proportion of respondents informed about the risk factors for diabetes varied from $58 \%$ in the $26-35$ age group to $75 \%$ in the $18-25$ age group and did not significantly differ between age groups. It can be said that, in general, the level of respondents' knowledge of the risk factors for diabetes is above average (Figure 3). 
Figure 3. The Level of Awareness of Risk Factors for Development of DM According to the Age Groups

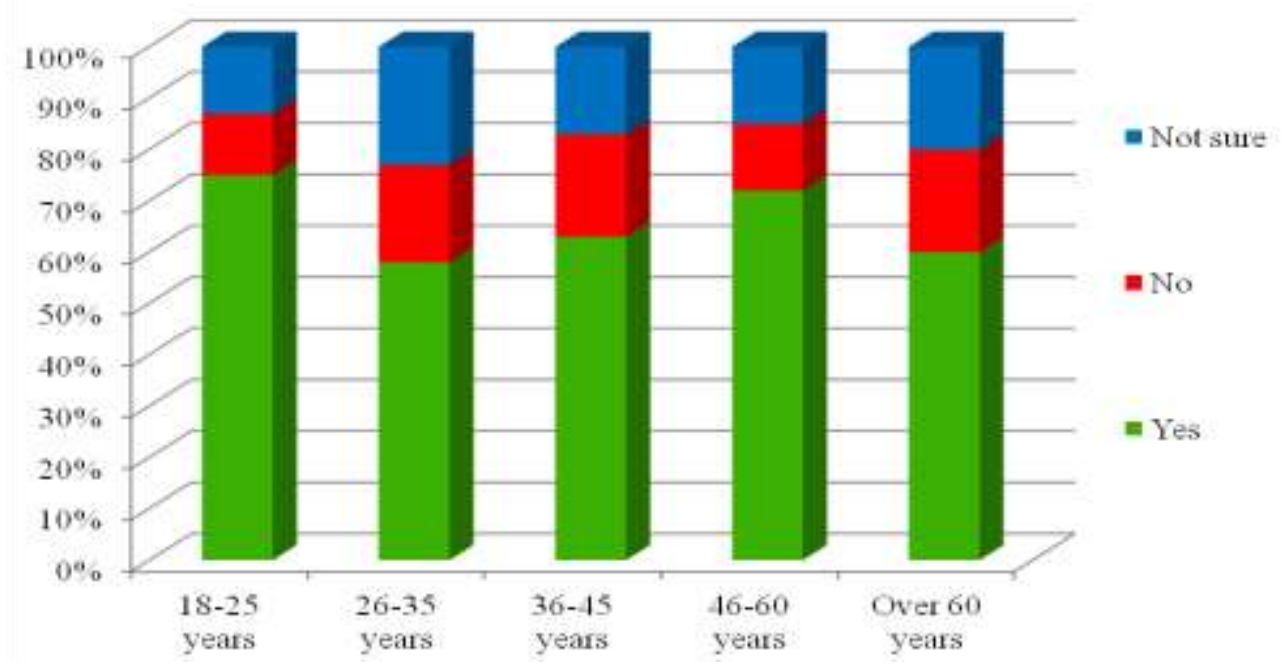

Source: Authors' estimations.

The proportion of people who was unsure or did not know at all about the risk factors for DM has ranged from $25 \%$ in the $18-25$ age group to $42 \%$ in the $26-35$ year old group.

Further, we asked if the respondents knew the symptoms of diabetes. Sixty two present of the respondents indicated that they were aware of the symptoms of DM (Figure 4). The rest of participants (38\%) noted that they did not know the symptoms of diabetes.

Figure 4. The Level of Awareness of DM Symptoms According to the Age Groups

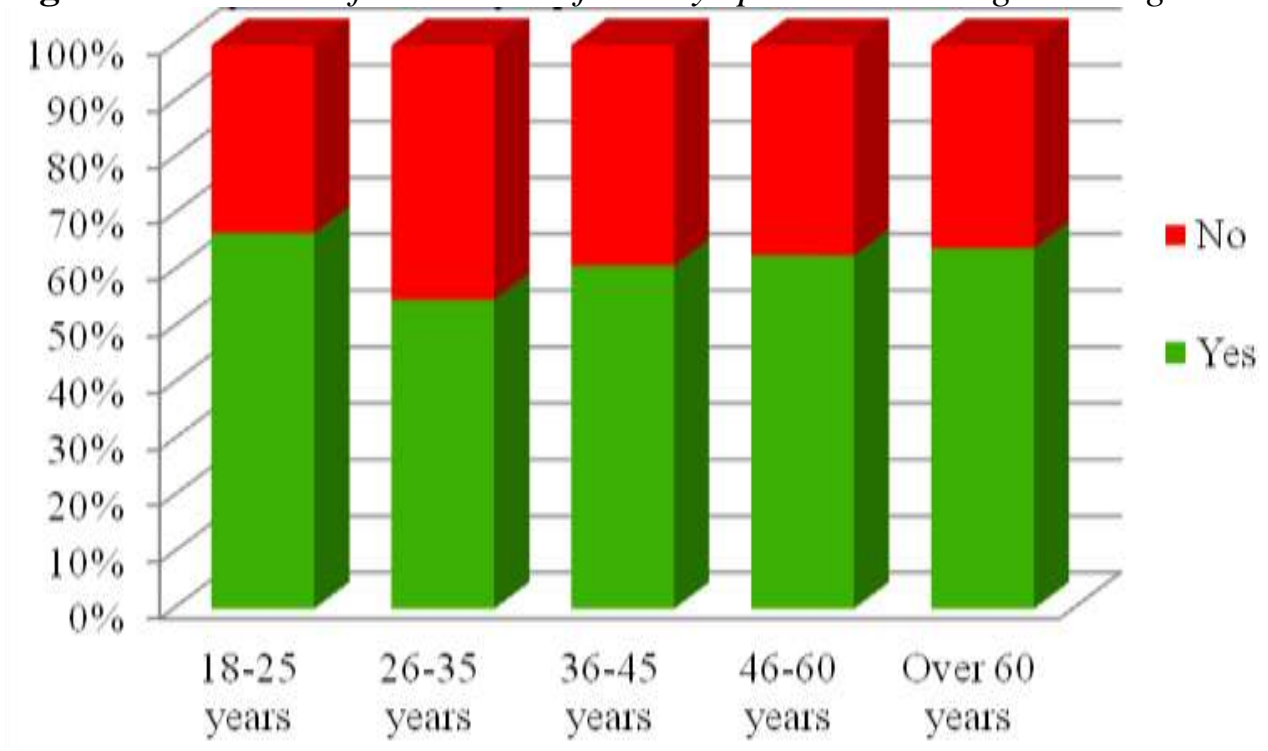

Source: Authors' estimations. 
In the course of the analysis of the population awareness of possible complications of diabetes, statistically significant differences among the age groups were not obtained. Forty seven percent of respondents indicated correctly the conditions that could complicate the course of diabetes. About a quarter of respondents found it difficult to answer about possible complications of diabetes. Twenty nine percent of respondents do not know about any complications of diabetes suggested in the answers.

Further, the issue of preventive measures, which the population takes in its daily life, was analyzed (Table 1). In the age groups of 46-60 years and over 60 years, the proportion of respondents who followed several recommendations for correcting behavioral risk factors (healthy nutrition; physical activity; rejection of "bad habits", such as smoking, alcohol and drugs consumption; annual blood test for glycemia level control) was $46 \%$ and $48 \%$, respectively. The lowest share in this indicator was in the age group of $36-45(37 \%)$, in the age groups of 18-25 years and 26-35 years, the share was $43 \%$ and $40 \%$, respectively. The analysis has showed that less than half of respondents observe several preventive recommendations in everyday life.

Table 1. Preventive Measures, which the Population Takes in its Daily Life

\begin{tabular}{|l|c|c|c|c|c|}
\hline \multirow{2}{*}{ Preventive measure } & \multicolumn{5}{|c|}{ Age group } \\
\cline { 2 - 6 } & $\begin{array}{c}18-25 \\
\text { years } \\
\text { old, \% }\end{array}$ & $\begin{array}{c}26-35 \\
\text { years old, } \\
\%\end{array}$ & $\begin{array}{c}36-45 \\
\text { years old, } \\
\%\end{array}$ & $\begin{array}{c}46-60 \\
\text { years old, } \\
\%\end{array}$ & $\begin{array}{c}\text { Over 60 } \\
\text { years old, } \\
\%\end{array}$ \\
\hline Healthy diet & 28 & 23 & 26 & 36 & 22 \\
\hline $\begin{array}{l}\text { Physical active } \\
\text { lifestyle }\end{array}$ & 25 & 13 & 9 & 13 & 18 \\
\hline $\begin{array}{l}\text { Cessation of smoking } \\
\text { and alcohol } \\
\text { consumption }\end{array}$ & 21 & 11 & 26 & 29 & 26 \\
\hline $\begin{array}{l}\text { Annual blood test for } \\
\text { glycemia level control }\end{array}$ & 0 & 0 & 22 & 19 & 28 \\
\hline Nothing & 9 & 16 & 9 & 3 & 8 \\
\hline
\end{tabular}

Source: Authors' estimations.

Attention is drawn to the fact that about $1 / 5(16 \%)$ of respondents aged from 26 to 35 do not follow the recommendations on healthy lifestyle, and the proportion of similar respondents aged form 46 to 60 years was less than $1 / 10$ $(3 \%)$, and this difference was statistically significant $(\mathrm{p}<0.02)$.

The number of tobacco smokers and people who consumes alcohol in the age group of 25-30 years constituted 56\%, and it was significantly higher $(\mathrm{p}<0.03)$ compared to other age groups. In the age group over 60 years, a significantly higher number of respondents $(74 \%)$ answered that they do not have a habit of smoking and alcohol consumption $(\mathrm{p}<0.01)$. This data indicates on a more conscious attitude to their health in older age groups.

The obtained results suggest a need for extension of public awareness campaigns and diabetes education programmes in order to intensify preventive 
measures and the motivation of the population to preserve and strengthen their health.

\section{Evaluation of the 10-year Risk of Developing T2DM}

The sample population for assessing the 10-year risk of T2DM development consisted of 244 patients, 75 (30.7\%) men and 169 (69.3\%) women. The greatest number of respondents is represented by the age group of $18-25$ years $-31 \%$. The share of the 26-35 age group was 21\%; 36 - 45 years old - 16\%. 46 - 60 years $19 \%$, over 60 years - $13 \%$ (Figure 5).

Figure 5. Distribution of Respondents by Age

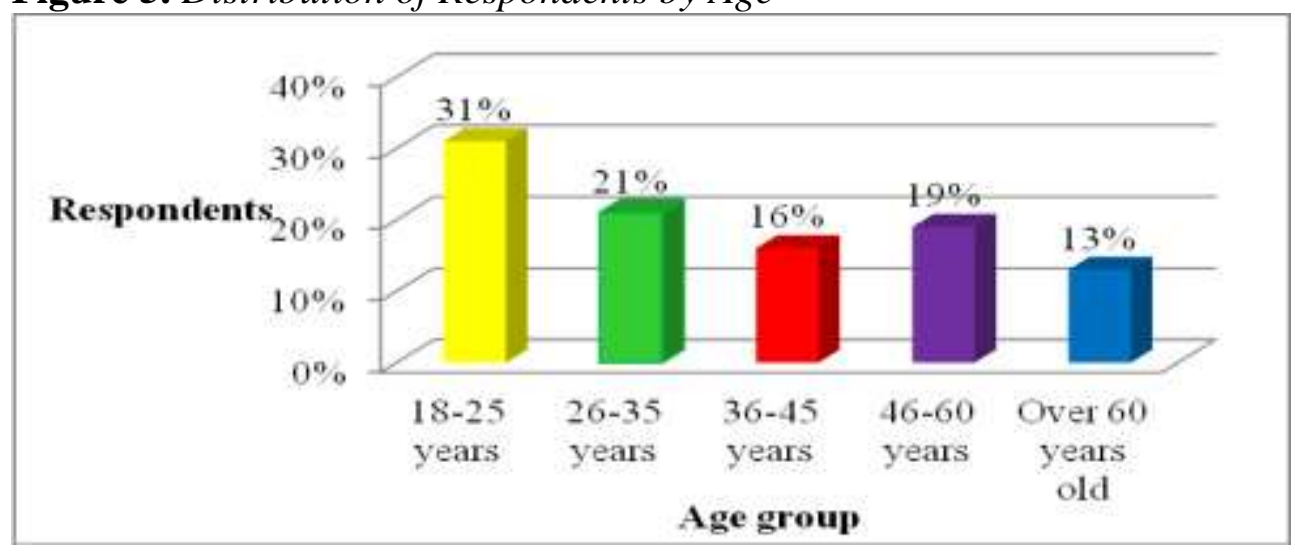

An analysis of the obtained data of assessment the 10-year risk of developing T2DM showed that $44 \%$ of respondents had a value of BMI that exceeded the upper limit of the norm of $24.9 \mathrm{~kg} / \mathrm{m}^{2}$, which confirms the high prevalence of overweight and obesity within the population who took part in the study (according to WHO data, the BMI value of $25-30 \mathrm{~kg} / \mathrm{m}^{2}$ is characteristic for excess body weight, and BMI $>30 \mathrm{~kg} / \mathrm{m}^{2}$ for obesity). With age, there was a tendency of the increase of the proportion of respondents with excessive body weight and obesity. The smallest number of people with overweight and obesity was recorded in the 18-25 age group (10\%). This value was significantly lower than in the age groups from 36 to 45 years $(50 \%, \mathrm{p}<0.00001)$, from 46 to 60 years $(80 \%$, $\mathrm{p}<0.0001)$ and over 60 years $(91 \%, \mathrm{p}<0.0001)$.

According to the recommendations of IDF experts, normal values of waist circumference in Europids women are less than $80 \mathrm{~cm}$, in men $-94 \mathrm{~cm}$. With a value of more than $88 \mathrm{~cm}$ in women and $94 \mathrm{~cm}$ in men, there is a high risk of developing type 2 diabetes mellitus and cardiovascular pathology (IDF 2006). Within the surveyed, the largest number of respondents (93\%) with normal waist circumference values was recorded in the 18-25 age group, which significantly differed with the age groups of $36-45$ years $(50 \%, \mathrm{p}<0.1), 46-60$ years $(24 \%$, $\mathrm{p}<0.0002)$ and over 60 years $(6 \%, \mathrm{p}<0.00001)$. Moreover, waist circumference $>102(88) \mathrm{cm}$ (characteristic for abdominal obesity and metabolic syndrome) was frequent within the subjects older than 46 years than WC 94-102 (80-88) cm. 
The most important behavioral factors characterizing the motivation of the population for healthy lifestyle are their physical activity and application of the principles of nutrition. According to the survey results, the largest proportion of people who observe the physical activity regime for at least 30 minutes a day is in the $18-25$ age group and is $83 \%$. In other age groups, there was a significant $(\mathrm{p}<0.0001)$ decrease in the proportion of people who noted the daily physical activity (Table 2).

Table 2. Prevalence of Risk Factors for Development of T2DM in Respondents of Different Age Groups

\begin{tabular}{|c|c|c|c|c|c|c|}
\hline \multirow[b]{2}{*}{ Risk factor } & \multirow[b]{2}{*}{$\begin{array}{l}\text { Possible } \\
\text { answer }\end{array}$} & \multicolumn{5}{|c|}{ Age group } \\
\hline & & $\begin{array}{c}18-25 \\
\text { years } \\
\text { old, } \%\end{array}$ & $\begin{array}{c}26-35 \\
\text { years } \\
\text { old, } \%\end{array}$ & $\begin{array}{c}36-45 \\
\text { years } \\
\text { old, } \%\end{array}$ & $\begin{array}{c}46-60 \\
\text { years } \\
\text { old, } \%\end{array}$ & $\begin{array}{c}\text { Over } 60 \\
\text { years } \\
\text { old, } \%\end{array}$ \\
\hline \multirow{3}{*}{$\begin{array}{l}\text { Body mass } \\
\text { index, } \mathrm{kg} / \mathrm{m}^{2}\end{array}$} & $<25$ & 89 & 75 & $50 * * * *$ & $20 * * *$ & $9 * * *$ \\
\hline & $25-30$ & 9 & 19 & 42 & 39 & 42 \\
\hline & $>30$ & 2 & 6 & 8 & 41 & 49 \\
\hline \multirow{3}{*}{$\begin{array}{l}\text { Waist } \\
\text { circumference, } \\
\text { cm }\end{array}$} & $<94(80)$ & 93 & 67 & $50 *$ & $24 * *$ & $6 * * * *$ \\
\hline & $\begin{array}{l}94-102 \\
(80-88) \\
\end{array}$ & 7 & 29 & 34 & 30 & 27 \\
\hline & $\begin{array}{l}>102 \\
(88)\end{array}$ & 0 & 4 & 16 & 46 & 67 \\
\hline \multirow{2}{*}{$\begin{array}{l}\text { Daily } \\
\text { availability of } \\
\text { 30-minute } \\
\text { activity }\end{array}$} & Yes & 83 & $67 * * *$ & $66 * * *$ & $63 * * *$ & $67 * * *$ \\
\hline & No & 17 & 33 & 34 & 37 & 33 \\
\hline \multirow{2}{*}{$\begin{array}{l}\text { How often do } \\
\text { you consume } \\
\text { vegetables? }\end{array}$} & $\begin{array}{c}\text { Every } \\
\text { day }\end{array}$ & 43 & 62 & 50 & 57 & 55 \\
\hline & $\begin{array}{l}\text { Not } \\
\text { every } \\
\text { day }\end{array}$ & 57 & 38 & 50 & 43 & 45 \\
\hline \multirow{2}{*}{$\begin{array}{l}\text { Have you had to } \\
\text { take } \\
\text { antihypertensive } \\
\text { drugs? }\end{array}$} & No & 99 & 98 & 87 & 63 & 15 \\
\hline & Yes & 1 & 2 & 13 & 37 & $85 * * * * *$ \\
\hline \multirow{2}{*}{$\begin{array}{l}\text { Have you ever } \\
\text { had an } \\
\text { increased level } \\
\text { of glucose? }\end{array}$} & No & 96 & 90 & 87 & 80 & 58 \\
\hline & Yes & 4 & 10 & 13 & 20 & $42 * * *$ \\
\hline $\begin{array}{l}\text { Was there any } \\
\text { diabetes } \\
\text { mellitus in your } \\
\text { family? }\end{array}$ & Yes & 28 & 25 & 43 & 26 & 30 \\
\hline
\end{tabular}

$* \mathrm{p}<0.1, * * \mathrm{p}<0.0002, * * * \mathrm{p}<0.0001, * * * * \mathrm{p}<0.00001, * * * * * \mathrm{p}<0.001$

Source: Authors' estimations.

Based on the evidence-based European guidelines for the prevention of T2DM, it has been shown that lifestyle modification, consisting only in reducing body weight and increasing physical activity, prevents or slows the progression of 
glucose metabolism disorders in persons with ITG. Therefore, people at high risk for T2DM and with the present ITG should be educated about the need for lifestyle modification and assistance in its implementation (Paulweber et al. 2010).

The survey data showed that daily consumption of vegetables was noted by the $43 \%$ respondents up to $62 \%$ respondents in the 18-25 age group and in the 2635 age group respectively. Attention is drawn to the fact that only half of the respondents (52\%), when analyzing the group as a whole, note the daily consumption of vegetables.

There was not significant difference in prevalence of family history of diabetes between the age groups. Thirty percent of all respondents indicated the presence of diabetes mellitus in family history.

As it was expected, the greatest number of people with a history of episodes of increased glycemia and constantly taking antihypertensive drugs was noted in the age group of 60 years and older, which was statistically significantly different from the age group of $18-25$ years $(\mathrm{p}<0.0001$ and $\mathrm{p}<0.001$, respectively).

To determine the factors that significantly affected the magnitude of 10year risk of T2DM, a linear regression was performed with the construction of a linear regression model taking into account the significance $(p<0.05)$ or the influence of selected predictors at the level of stable trends $(\mathrm{p}<0.1)$.

The age $(b=0.21, p<0.0001)$ had a significant effect on the growth of the 10-year risk of DM development, moreover the highest risk was determined in the age group of 36-45 years - young able-bodied population.

Also, an increase in the 10-year risk of development of T2DM was influenced by the values of BMI $(b=0.39 ; p<0.0001)$ and waist circumference $(b=0.41 ; p<0.0001)$. Regression analysis shows that a 10 -year risk of developing type T2DM increases not only with obesity, but also at the stage of overweight.

The lack of physical activity had a significant impact on the growth of the 10 -year risk of developing T2DM $(b=0.19 ; p<0.01)$. Among respondents who indicated regular physical activity, the median risk for developing T2DM was 3.00 and was significantly lower than the median of respondents who did not have physical activity $8.00(\mathrm{Z}=-3.25 ; \mathrm{p}<0.001)$. As it was shown earlier, in the age groups older than 26 years there was a decrease in the proportion of people who indicated the presence of daily physical activity.

The lack of vegetables in the daily diet increased the risk of T2DM at the level of a stable trend $(b=0.11 ; p=0.054)$. Respondents who consumed vegetables on a daily basis had a risk median of 3.00 and it was significantly lower than the median risk of respondents who did not consume vegetables daily $4.50(\mathrm{Z}=-1.87$; $\mathrm{p}<0.04$ ), with a specific gravity of about half all age groups.

The presence of hypertension requiring medication correction had a significant impact on the growth of the 10-year risk of developing T2DM $(b=0.37 ; p<0.0001)$. In respondents who did not take antihypertensive drugs on a regular basis, the risk median was 3.00 and it was significantly lower against the median of respondents suffering from $\mathrm{AH} 8.50(\mathrm{Z}=-5.66 ; \mathrm{p}<0.000001)$. The average risk for respondents who had an anamnesis without episodes of hyperglycemia was $3.00(0.00 ; 7.00)$ and it was significantly lower than the median of respondents who had transient hypoglycemia disorders 8.50 ( $\mathrm{Z}=$ - 
$2.11 ; \mathrm{p}<0.0001)$. The greatest number of people taking antihypertensive drugs and noting an increase in the level of glycemia was noted in the age group over 60 years.

In addition, an analysis was made of the likelihood of developing T2DM in different age groups of patients (Table 3, Figure 6).

Table 3. Structure of a 10-year Risk of Developing T2DM

\begin{tabular}{|l|l|c|c|c|c|c|}
\hline \multirow{2}{*}{$\begin{array}{l}\text { Risk of development of } \\
\text { type 2 DM }\end{array}$} & $\begin{array}{c}18-25 \\
\text { years, \% }\end{array}$ & $\begin{array}{c}26-35 \\
\text { years, \% }\end{array}$ & $\begin{array}{c}36-45 \\
\text { years, \% }\end{array}$ & $\begin{array}{c}46-60 \\
\text { years, \% }\end{array}$ & $\begin{array}{c}\text { Over 60 } \\
\text { years, \% }\end{array}$ \\
\hline Low & $\begin{array}{l}\text { Lower than } \\
7 \text { points }\end{array}$ & 95 & 81 & 63 & 20 & 1 \\
\hline $\begin{array}{l}\text { Slightly } \\
\text { elevated }\end{array}$ & $\begin{array}{l}7-11 \\
\text { points }\end{array}$ & 5 & 13 & 21 & 48 & 30 \\
\hline Moderate & $12-14$ points & 0 & 4 & 8 & 13 & 24 \\
\hline High & $15-20$ points & 0 & 2 & 8 & 15 & 27 \\
\hline Very high & $\begin{array}{l}\text { Higher } \\
\text { than 20 }\end{array}$ & 0 & 0 & 0 & 4 & 18 \\
\hline
\end{tabular}

Source: Authors' estimations.

In the age groups of 18-25 years, 26-35 years and 36-45 years, the overwhelming majority of respondents had a low risk of developing T2DM (lower than 7 points), and a very high risk (higher than 20 points) was not registered at all. Among the population 46 years and older there was a shift towards a moderate level of risk increase (from 12 points).

Figure 6. Structure of a 10-year Risk of Developing T2DM

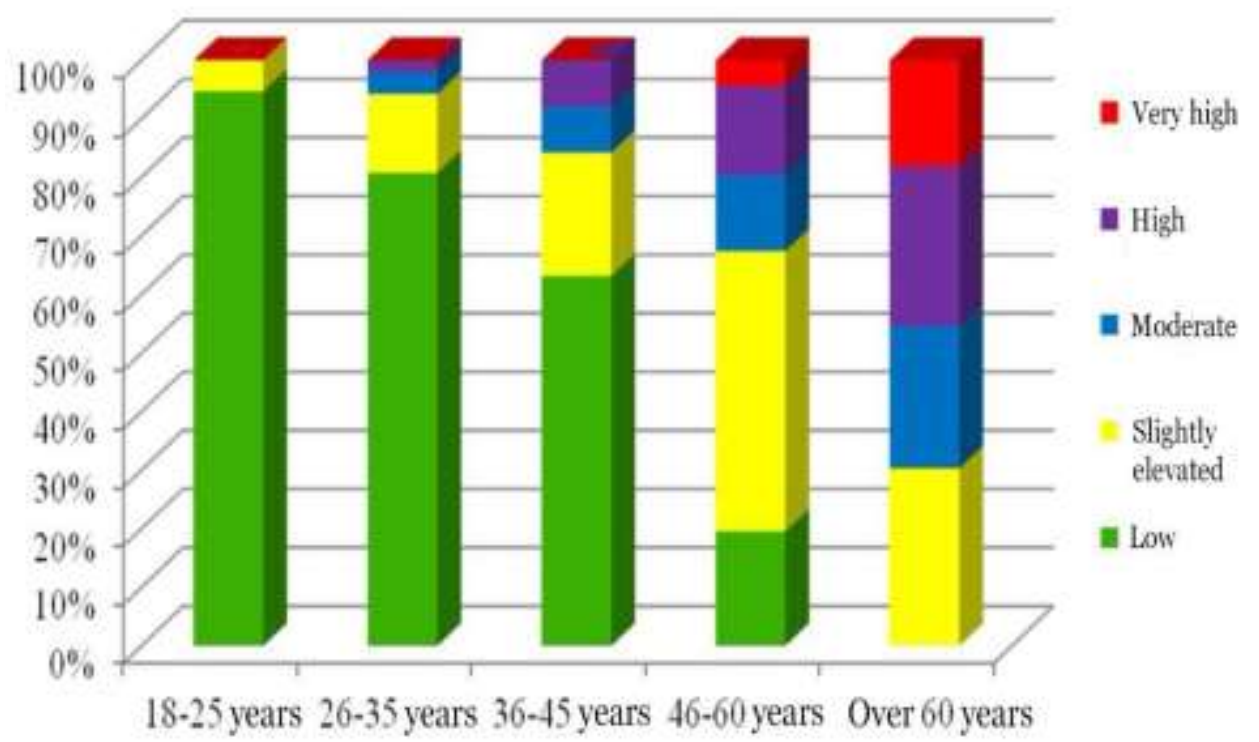

Source: Authors' estimations.

In the age groups of 46-60 years and over 60 years there was an increase in the number of people with a moderate and high risk of developing T2DM. In the 
age group over 60 years, there was registered the greatest proportion of people with high and very high risk, which amounted to $27 \%$ and $18 \%$, respectively. This trend is due to a combination of risk factors in these age groups. It should be noted that the most significant factors that significantly influenced the risk of developing T2DM were controlled behavioral factors, namely: BMI, WC, adherence to proper nutrition and physical activity.

Further, some data were compared that were obtained during the analysis of the level of awareness of the population on DM issues and an assessment of the 10 -year risk of developing T2DM. It is noteworthy that $66 \%$ of respondents indicated that they know about the risk factors for the development of the disease, of which only $43 \%$ observe several recommendations on healthy lifestyle, including healthy diet, a physically active lifestyle and a refusal to smoke and alcohol consumption. There was shown that these parameters (BMI, WC, daily 30-minute activity and vegetables in the diet) had the most significant impact on the 10-year risk of developing T2DM.

Obtained results may indicate to lack of motivation of population to take care about their health. Efforts to improve knowledge about diabetes, increase promotion of healthy behaviors and availability of changing lifestyle programs are needed to slow the growth in new cases of diabetes (Geiss et al. 2010).

\section{Study of Psychosomatic Relationships in Diabetes}

246 respondents aged 18-55 were interviewed, 126 of them had T2DM with a duration of more than 5 years, 120 - persons without diabetes. The median of the BMI was $28.81(23.51,32.65) \mathrm{kg} / \mathrm{m}^{2}$ : with T2DM - BMI $29.12(24.48,33.35)$ $\mathrm{kg} / \mathrm{m}^{2}$; in persons without T2DM $-27.92(22.85,31.26) \mathrm{kg} / \mathrm{m}^{2}$.

Comparative analysis of the eating behavior of patients with T2DM and individuals without T2DM showed no statistically significant differences in the groups. At the same time, respondents with normal body weight and overweight/ obesity have differences in all scales of questionnaire of the eating behavior: restrictive eating behavior $\mathrm{p}<0.05$; emotiogenic eating behavior $\mathrm{p}<0.005$; external eating behavior $\mathrm{p}<0.005$.

Among the respondents with overweight and obesity, there was identified the following distribution styles of eating behavior: the leading eating style (the predominance of emotional, external or restrained eating) was verified in $70.3 \%$ of cases; mixed eating style - in $23.5 \%$; there were not detected eating disorders in $6.2 \%$. Among the individuals with the presence of leading style of food, there was noted the predominance of emotiogenic style $-48.6 \%$, the second place took the external eating style of $31.4 \%$, and the third - the restrictive type $-20.0 \%$.

Significant differences in styles of eating behavior have been identified depending on gender: women were significantly more likely to have an emotiogenic style (identified in 117 women, versus 55 men; $\chi^{2}=16.71 ; p<0.0001$ ), the incidence among women and men of external style and restrictive style. Therefore, the styles of eating behavior do not differ depending on the presence or absence of DM and mediate the relationship between the personality characteristics of respondents with overweight. Women, in comparison with men, 
are dominated by an emotiogenic style of eating behavior, a stimulus to food intake, which becomes not a hunger, but emotional discomfort: anxiety, irritability, bad mood, a sense of loneliness.

In the study of psychoemotional status, there was established that subclinical and clinically expressed manifestations of anxiety in persons without T2DM are significantly less frequent ( 28 cases per 120 people) than in individuals with T2DM ( 50 cases per 126 people; $\chi^{2}=3.96 ; p<0.05$ ). The incidence of subclinical and clinically significant manifestations of depression was about $5.0 \%$ in patients with T2DM and without DM. A significant direct correlation was found in the incidence of clinically significant anxiety with the emotionogenic type of eating behavior in women who are overweight or obese $(\mathrm{rS}=0.49 ; \mathrm{p}<0.05)$. At the same time, the correlation analysis demonstrated the absence of an interrelation of the psychoemotional status of men with the types of eating behavior depending on BMI and the presence of T2DM.

The study of psychoemotional status demonstrated that the majority of overweight people, even in the absence of T2DM, are in a state of disadaptation and psychoemotional stress.

Absolute majority of patients with T2DM (84.62\%) and persons without T2DM (83.17\%) showed high resistance to stress. At the same time, the proportion of people with a high level of stress among patients T2DM is higher than without T2DM $\left(\chi^{2}=4.20 ; p=0.04\right)$. In 15 patients with T2DM, a high level of stress was detected, whereas in 5 patients without T2DM there was detected a high level of stress. This may indicate to the high psychoemotional tension and difficulties in overcoming negative psychological situations in T2DM.

Alexithymia - reduced ability in verbalization of emotional states and feelings - is characteristic of people who, for one reason or another, are limited in processing, and therefore aware of emotional impressions, experiences, feelings, causes of actions. Among the subjects studied, the non-lecithiemic type of personality was recorded in $81.58 \%$ of cases among persons without T2DM and in $79.23 \%$ with T2DM ( $>0.05)$. In 29 patients with $\mathrm{BMI} \geq 25 \mathrm{~kg} / \mathrm{m}^{2}$ the Alexitimic personality type was diagnosed (74 points and higher), with BMI $<25 \mathrm{~kg} / \mathrm{m}^{2}-$ in 11 examined. Alexithymic type of personality was significantly more common in cases of overweight or obesity $\left(\chi^{2}=6.28 ; p=0.01\right)$. In addition, when conducting a correlation analysis, the "Alexitimic" personality type showed a direct significant connection with clinically significant anxiety $(\mathrm{rS}=0.34 ; \mathrm{p}<0.042)$.

\section{Discussion and Conclusion}

One of the objectives of the present study was to assess the awareness of the population about the diabetes and preventive measures of this pathology. The obtained results demonstrate the gaps of knowledge on some issues: $33 \%$ of respondents of population are not informed about the risk factors for diabetes, $38 \%$ - about the first signs of the disease; $29 \%$ - of possible complications. Similar study for awareness of type 2 diabetes risk factors and prevention strategies among low-income Latinos in Lawrence (Massachusetts) have shown that this Latino 
sample had limited knowledge of diabetes risk factors and lifestyle changes that can prevent or delay diabetes onset. Moreover, the limited awareness of diabetes risk factors in this sample was paralleled by the limited knowledge of strategies to prevent or delay diabetes onset (Rosal et al. 2011). Therefore, an insufficient level of awareness of the population on diabetes mellitus issues leads to low alertness in relation to risk factors and clinical manifestations.

Study findings demonstrated that $66 \%$ of respondents were aware of the risk factors of T2DM, but only $43 \%$ of them follow several recommendations on healthy lifestyle (diet, a physically active lifestyle and cessation of smoking and alcohol consumption). This data may indicate that low adherence to healthy lifestyle among the population is due not only to ignorance, but also to a lack of desire to change behavioral determinants and underestimation of existing risk factors.

The study of psychoemotional status demonstrated that the majority of overweight people, even in the absence of T2DM, are in a state of disadaptation and psychoemotional stress, which can be a risk factor for the development of a deficit of compensatory resources of the body and the emergence of psychosomatic diseases. Recent literature suggests that stress and emotional distress are perceived as triggers for diabetes (Coronado et al. 2004, Jezewski and Poss 2002, George et al. 2005, Mier et al. 2007), as well as depressed individuals are less likely to succeed at lifestyle change efforts and that depression may independently contribute to the development of diabetes (Engum 2007, Rosal et al. 2011). This group of people requires not only monitoring the laboratory indicators of carbohydrate and lipid metabolism, but also in the framework of preventive work of carrying out psycho-corrective measures aimed at normalizing the psychoemotional state with the goal of preventing diseases, which may be based on psychosomatic conditions.

To have a significant public health impact, tailored programs at the individual level must be matched by changes in policy and the physical and social environments in a truly multilevel approach (Castro et al. 2009). Prevention of T2DM should begin with convincing the public of the need to modify the lifestyle and habitual settings, and be implemented both at the level of the population as a whole and at the individual level. An important point is to increase the motivation of the population to a more conscious attitude to their own health. When patient characteristics are assessed and understood, health care providers are presented with an opportunity to influence patient efficacy beliefs (Thomas et al. 2016). At the same time, information of preventive and motivational orientation should be accessible and clearly formulated. Presented materials other than general phrases, such as: reducing overweight, optimizing physical activity, healthy eating, should contain specific recommendations for lifestyle modification.

Previous studies have shown that providing patients specific information about their risk of developing diabetes and the expected risk reduction associated with preventive treatments may encourage lifestyle changing. New guidelines and evidence recommend the personalized approach (patient-centered dialogue) to helping patients make treatment decisions (O'Brien et al. 2016). 
Therefore, preventive measures in relation to DM should be based on a strategy of long-term and multistage work with certain segments of the population, based on knowledge of the behavioral and psychological characteristics of this population, knowledge of its motivations and interests.

\section{Limitations of the Study}

We obtained interesting results during the study of psychosomatic status of patients with T2DM and without diabetes. But the sample of population was quite small, so it needs to be examined in fuller detail.

\section{References}

ADA-American Diabetes Association (2015) Diabetes Care 38(Suppl. 1): S8-S16.

ADA-American Diabetes Association (2014) Diagnosis and Classification of Diabetes Mellitus. Diabetes Care 37(Suppl. 1): S81-S90

ADA-American Diabetes Association (2017) Standards of Medical Care in Diabetes. Diabetes Care 40(1): 1-94.

Bagby RM, Taylor GJ, Ryan D (1986) Toronto Alexithymia Scale: Relationship with Personality and Psychopathology Measures Psychotherapy and Psychosomatics 45(4): 207-215.

Bansal N (2015) Prediabetes Diagnosis and Treatment: A Review. World Journal of Diabetes 6(2): 296-303.

Barrada RJ, van Strien T, Cebolla A (2016) Internal Structure and Measurement Invariance of the Dutch Eating Behavior Questionnaire (DEBQ) in a (Nearly) Representative Dutch Community Sample European Eating Disorders Review 24(6): 503-509.

Castro FG, Shaibi GQ, Boehm-Smith E (2009) Ecodevelopmental Contexts for Preventing Type 2 Diabetes in Latino and other Racial/ethnic Minority Populations. Journal of Behavioral Medicine 32: 89-105.

Cebolla A, Barrada JR, van Strien T, Oliver E, Baños R (2014) Validation of the Dutch Eating Behavior Questionnaire (DEBQ) in a sample of Spanish women Appetite 73(1): 58-64.

Coronado GD, Thompson B, Tejeda S, Godina R (2004) Attitudes and Beliefs among Mexican Americans about Type 2 Diabetes. Journal of Health Care Poor and Underserved 15(4): 576-588.

Dedov II, Shestakova MV (2013) Federal Targeted Programme "Prevention and Management of Socially Significant Diseases (2007-2012)": results of the "Diabetes mellitus" subprogramme. Diabetes Mellitus 16(2S): 1-48.

Engum A (2007) The Role of Depression and Anxiety in Onset of Diabetes in a Large Population-based Study. Journal of Psychosomatic Research 62(1): 31-38.

Falco G, Pirro PS, Castellano E, Anfossi M, Borretta G, et al. (2015) The Relationship between Stress and Diabetes Mellitus. Journal of Neurology Psychology 3(1): 7.

Geiss LS, James C, Gregg EW, Albright A, Williamson DF, Cowie CC, et al. (2010) Diabetes Risk Reduction Behaviors among US Adults with Prediabetes American Journal of Preventive Medicine 38(4):403-409. 
George GC, Milani TJ, Hanss-Nuss H, Freeland-Graves JH (2005) Compliance with Dietary Guidelines and Relationship to Psychosocial Factors in Low-income Women in Late Postpartum. Journal of American Dietary Association 105(6): 916-926.

Holmes TH, Rahe RH (1967) The Social Readjustment Rating Scale. Journal of Psychosomatic Research 11(2): 213-221.

Hopper I, Billah B, Skiba M, Krum H (2011) Prevention of Diabetes and Reduction in Major Cardiovascular Events in Studies of Subjects with Prediabetes: Meta-analysis of Randomised Controlled Clinical Trials. European Journal of Cardiovascular and Preventive Rehabilitation 18(6): 813-823.

IDF-International Diabetes Federation (2011) Diabetes Atlas, Fifth Edition. Brussels: IDF.

IDF-International Diabetes Federation (2006) International Diabetes Federation Consensus Worldwide Definition of the Metabolic Syndrome. Brussels: IDF.

Jezewski MA, Poss J (2002) Mexican Americans' Explanatory Model of Type 2 Diabetes. West Journal of Nursing Research 24(8): 840-858.

Knowler WC, Barrett-Connor E, Fowler SE, Hamman RF, Lachin JM, Walker EA et al. (2002) Diabetes Prevention Program Research Group. Reduction in the Incidence of Type 2 Diabetes with Lifestyle Intervention or Metformin. New England Journal of Medicine 346(6): 393-403.

Li G, Zhang P, Wang J, Gregg EW, Yang W, Gong Q, et al. (2008) The Long-term Effect of Lifestyle Interventions to Prevent Diabetes in the China Da Qing Diabetes Prevention Study: A 20-year Follow-up Study. Lancet 371(9626): 1783-1789.

Lindström J, Ilanne-Parikka P, Peltonen M, Aunola S, Eriksson JG, Hemiö K, et al. (2006) Sustained Reduction in the Incidence of Type 2 Diabetes by Lifestyle Intervention: Follow-up of the Finnish Diabetes Prevention Study. Lancet 368(9548): 1673-1679.

Lindström J, Tuomilehto J (2003) The Diabetes Risk Score Diabetic Care 26(3): 725731.

Mier N, Medina AA, Ory MG (2007) Mexican Americans with Type 2 Diabetes: Perspectives on Definitions, Motivators, and Programs of Physical Activity. Preventive Chronic Disease 4(2): A24.

Natangelo R, Luè D, Bianchi GB, Ronchi E, Conti D (1990) The Hypoglycemic Reactions in Diabetic Patients in the Emergency Room. Which Patients are going to be Hospitallized? Minerva Medicine 81(7-8): 561-565.

O'Brien MJ, Moran MR, Tang JW, Vargas MC, Talen M, Zimmermann LJ, et al. (2016) Patient Perceptions About Prediabetes and Preferences for Diabetes Prevention. The Diabetes Educator 42(6): 667-677.

Ogurtsova K, da Rocha Fernandes JD, Huang Y, Linnenkamp U, Guariguata L, Choa NH, et al. 2017 IDF Diabetes Atlas: Global Estimates for the Prevalence of Diabetes for 2015 and 2040. Diabetes Research and Clinical Practice 128: 40-50.

Paulweber B, Valensi P, Lindström J, Lalic NM, Greaves CJ, McKee M, et al. (2010) A European Evidence-Based Guideline for the Prevention of Type 2 Diabetes. Hormone and Metabolic Research 42: S3-S36.

Poberey DN, Mellina TV (2012) Psychosomatic Aspects of Diabetes Mellitus Developing Clinical Medicine 1: 105-108.

Rosal MC, Borg A, Bodenlo JS, Tellez T, Ockene IS (2011) Awareness of Diabetes Risk Factors and Prevention Strategies among a Sample of Low-Income Latinos With No Known Diagnosis of Diabetes. The Diabetes Educator 37(1): 47-55.

Rydén L, Grant PJ, Anker SD, Berne C, Cosentino F, Danchin N, et al. (2014) ESC Guidelines on Diabetes, Pre-diabetes, and Cardiovascular Diseases Developed in Collaboration with the EASD. Russian Journal of Cardiology 3(107): 7-61. 
Saaristo T, Peltonen M, Lindstrom J, Saarikoski L, Sundvall J, et al. (2005) CrossSectional Evaluation of the Finnish Diabetes Risk Score: A Tool to Identify Undetected Type 2 Diabetes, Abnormal Glucose Tolerance and Metabolic Syndrome. Diabetes and Vascular Disease Research 2(2): 67-72.

Stern AF (2014) The Hospital Anxiety and Depression Scale. Occupational Medicine 64(5): 393-394.

Stratton IM, Adler AI, Neil HAW, Matthews DR, Manley SE, Cull CA, et al. (2000) Association of Glycaemia with Macrovascular and Microvascular Complications of Type 2 Diabetes: Prospective Observational Study. British Medical Journal 321: 405-412.

Thomas JJ, Moring JC, Harvey T, Hobbs T, Lindt (2016) A Risk of Type 2 Diabetes: Health Care Provider Perceptions of Prevention. Applied Nursing Research 32: 16.

Williams MV, Baker DW, Parker RM (1998) Differences in Disease Knowledge between Patients with Adequate and Inadequate Functional Health Literacy. Archives of Internal Medicine 158: 166-172.

WHO-World Health Organization (1999) Definition, Diagnosis and Classification of Diabetes Mellitus and its Complications. Report of a WHO Consultation. WHO Geneva.

WHO-World Health Organization (2013) Health Literacy: The Solid Facts. WHO Geneva.

WHO-World Health Organization (2016) Global Report on Diabetes. WHO Geneva.

WHO-World Health Organization (2017) Prevalence of Noncommunicable Disease Risk Factors in Republic of Belarus. STEPS 2016 (2017). Retrieved from https://bit. ly/2xm5JXA.

Wolf MS, Gazmararian JA, Baker DW (2005) Health Literacy and Functional Health Status Among Older Adults. Archives of Internal Medicine 165(17): 1946-1952.

Zhang L, Zhang Z, Zhang Y, Hu G, Chen L (2014) Evaluation of Finnish Diabetes Risk Score in Screening Undiagnosed Diabetes and Prediabetes among US Adults by Gender and Race: NHANES 1999-2010. PLoS One 9(5), e97865.

Zigmond AS, Snaith RP (1983) The Hospital Anxiety and Depression Scale. Acta Psychiatrica Scandinavica 67(6): 361-370. 
